Hydrol. Earth Syst. Sci., 15, 1023-1034, 2011

www.hydrol-earth-syst-sci.net/15/1023/2011/

doi:10.5194/hess-15-1023-2011

(C) Author(s) 2011. CC Attribution 3.0 License.

\title{
Rain event properties at the source of the Blue Nile River
}

\author{
A. T. Haile ${ }^{1,2}$, T. H. M. Rientjes ${ }^{1}$, E. Habib ${ }^{2}$, V. Jetten ${ }^{1}$, and M. Gebremichael ${ }^{3}$ \\ ${ }^{1}$ Department of Water Resources, Faculty of Geoinformation Science and Earth Observation, University of Twente, \\ P.O. Box 6, Enschede, 7500AA, The Netherlands \\ ${ }^{2}$ Department of Civil Engineering, University of Louisiana at Lafayette, Lafayette, LA 70504, USA \\ ${ }^{3}$ Department of Civil and Environmental Engineering, University of Connecticut, Storrs, CT 06269, USA
}

Received: 31 July 2010 - Published in Hydrol. Earth Syst. Sci. Discuss.: 17 August 2010

Revised: 7 December 2010 - Accepted: 9 March 2011 - Published: 24 March 2011

\begin{abstract}
In the present study, spatial and temporal patterns of rain event properties are analysed. These event properties are rain event depth, event duration, mean event rain rate, peak rain rate and the time span between two consecutive rain events which is referred to as inter-event time (IET). In addition, we assessed how rain event properties change when the period over which rainfall data is aggregated changes from 1 to $6 \mathrm{~min}$ and when the minimum inter-event time (MIT) changes from $30 \mathrm{~min}$ to $8 \mathrm{~h}$. Rainfall data is obtained from a field campaign in two wet seasons of June-August (JJA) of 2007 and 2008 in Gilgel Abbay watershed that is situated at the source basin of the Upper Blue Nile River in Ethiopia. The rainfall data was automatically recorded at eight stations. The results revealed that rain event depth is more related to peak rain rate than to event duration. At the start and towards the end of the wet season, the rain events have larger depth with longer duration and longer IET than those in midseason. Event rain rate and IET are strongly related to terrain elevation. Sekela which is on a mountain area has the shortest IET while Bahir Dar which is at the south shore of Lake Tana has the longest IET. The period over which rainfall data is aggregated significantly affected the values of rain event properties that are estimated using relatively small value ( $30 \mathrm{~min}$ ) of MIT but its effect diminished when the MIT is increased to $8 \mathrm{~h}$. It is shown that increasing the value of MIT has the largest effect on rain event properties of mountain stations that are characterised by high rainfall intermittency.
\end{abstract}

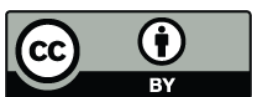

Correspondence to: A. T. Haile (haile07634@itc.nl)

\section{Introduction}

An understanding of rain event properties at specific spatiotemporal scales is of great importance for hydrology as well as for climate studies. According to Brown et al. (1985), rain events are a convenient way of summarizing a time series of rainfall amounts into entities that are defined so that they are meaningful in terms of a particular application. Such applications include studies of runoff generation (e.g. Milly and Eagelson, 1987; Kusumastuti et al., 2007; Reggiani and Rientjes, 2005, 2010; Zhang et al., 2005; de Vos and Rientjes, 2008), soil erosion (e.g. Angel et al., 2005), interception losses (e.g. Zeng et al., 2000) and rainfall modeling (e.g. Wooliser and Osborn, 1985; Haile et al., 2010b, Abdo et al., 2009).

Properties of single rain events such as mean event rain rate and event duration often vary at scales much smaller than a watershed scale and directly affect runoff mechanisms and related processes. For a synthetic watershed, Kusumastuti et al. (2007) showed that variability within a rain event which is referred to as intra-event variability can largely affect quick runoff processes and consequently flood generation. Menabde and Sivapalan (2001) showed that runoff discharge is proportional to the watershed area for relatively small watersheds with a response time less than the mean duration of rain events.

Rain event properties often serve as main inputs to soil erosion studies, e.g. Diodato and Bellocchi (2007). A lack of long-term rainfall records at the required spatial and temporal resolution, however, often restricts the applicability of erosion models in many regions. van Dijk et al. (2005) states that this problem has been overcome in two ways: (i) by using synthetic time series of rain events, or (ii) by

Published by Copernicus Publications on behalf of the European Geosciences Union. 
using empirical relations between hydrological model variables and more readily available rainfall characteristics (see Renard and Freimund, 1994; Diodato and Bellocchi, 2007). The use of synthesized or empirical relations to derive rain event properties can benefit from an understanding of these properties through analysis of actual rainfall measurements. In addition, the calibration of rainfall disaggregation models requires availability of short-term sub-daily records at one or more rain gauge stations, e.g. Arnaud et al. (2007) and Koutsoyiannis and Onof (2001).

Data from only one or two rain gauge stations may not be adequate to evaluate spatial patterns of rain event properties (see Brown et al., 1985; Tsubo et al., 2005). To analyze effects of terrain attributes such as elevation on rain event properties (see Loukas and Quick, 1996; Palecki et al., 2005) records from spatially distributed rain gauge stations are required. Information on rain event properties is not commonly available and studies that report on the spatial and temporal patterns of rain event properties are absent for many geographic locations which also applies to the Upper Blue Nile basin in East Africa.

As part of the present study, a network of 10 automatic rain gauges was set up in May 2007 at the source basin of the Upper Blue Nile River. From the network, eight stations recorded rainfall data of the full wet season of 2007, i.e. June-August (JJA) while only 2 rain gauges recorded the full wet season of 2008. The remaining gauges did not record the full season rainfall probably since they were damaged by local people.

In Haile et al. (2009), the orientation of the rain gauges in the study area is presented and the spatial pattern of the diurnal cycle of the basin rainfall is analyzed which showed that both orography and the presence of Lake Tana affect the spatial pattern of the diurnal cycle of rain frequency and rain rate. Haile et al. (2010a) showed that runoff simulations in the basin are largely sensitive to rainfall representation and reported runoff volume errors as large as $15-40 \%$ when the model input is only from 3-5 rain gauges instead of 8 rain gauges. Although these studies indicated the importance of understanding rain event properties in the study area, an explicit analysis of these properties is still lacking.

Rain event properties that are of general interest to the study of hydrological processes are rain event depth, rain rate, duration and inter-event time (IET).We analyzed temporal patterns of these rain event properties using rainfall records of Jema station which recorded rainfall data for the wet season of the years 2007 and 2008. This station is situated at an intermediate location between the mountains of Gilgel Abbay watershed and Lake Tana. Haile et al. (2010a) suggested that Jema station should be part of any rain gauge network that is applied to estimate rainfall input to a runoff model in this area. In this study the spatial patterns of rain event properties are evaluated using data from eight stations that recorded the JJA 2007 rainfall. We note that the rainfall amount of JJA 2007 is only $\sim 5 \%$ smaller than that of the

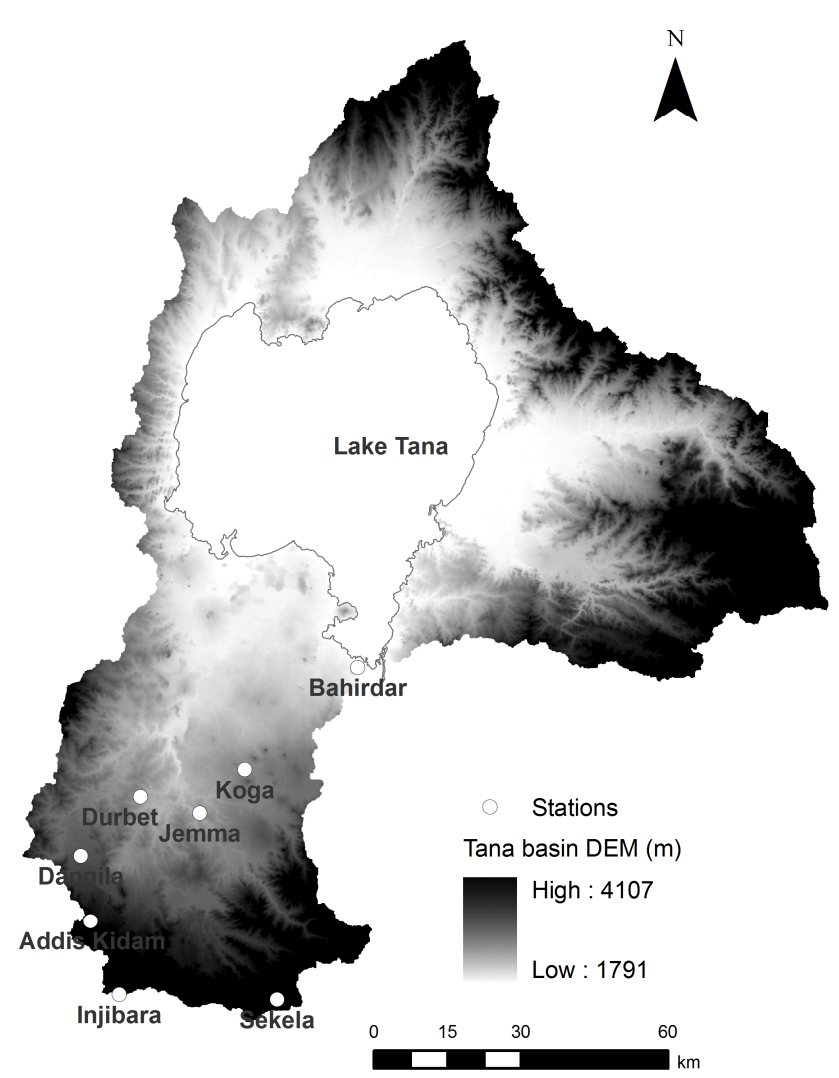

Fig. 1. The Lake Tana basin area and the location of the rain gauge stations.

long-term rainfall amount in the watershed indicating that the analysis period represents a nearly-normal period. The JJA 2008 rainfall amount at Jema is $8 \%$ smaller compared to that of 2007.

\section{Study area}

The Upper Gilgel Abbay watershed is located between $10^{\circ} 56^{\prime}$ to $11^{\circ} 22^{\prime} \mathrm{N}$ latitude and $36^{\circ} 44^{\prime}$ to $37^{\circ} 03^{\prime} \mathrm{E}$ longitudes. The main wet season of the area is from June to September while its main dry season is from October to May. Figure 1 shows a Shuttle Radar Topography Mission (SRTM) Digital Elevation Model (DEM) and locations of rain gauges.

The inter-annual distribution of rainfall in the study area is mainly affected by the location of the Intertropical Convergence Zone (ITCZ) which is caused by a low-level wind convergence. Haile et al. (2009) showed that orography and the presence of Lake Tana affect the diurnal cycle of rainfall frequency and rate in the study area resulting in afternoon maximum rain frequency and rain rate over mountain areas and nocturnal maximum over lowland areas near the lake. The authors also showed that rainfall of the study area has mainly convective origin. 


\section{Methods}

Criteria to identify rain events often rely on threshold values for selected properties of rain events. For instance, event duration and rain rate may serve to identify events (see Dunkerley, 2008b). Commonly, thresholds for minimum inter-event time (MIT) and minimum event depth serve to identify rain events or to classify a series of rain observations as rain events. Dunkerley $(2008 \mathrm{a}, \mathrm{b})$ reviewed a large number of criteria and reported that the applied MIT varies from $3 \mathrm{~min}$ to $24 \mathrm{~h}$ while the minimum event depth varies from measurable amount (e.g. $0.2 \mathrm{~mm}$ for rain gauges used in the present study) to $13.0 \mathrm{~mm}$. A consequence of a change in criterion for instance could be that event rain rate may decrease as MIT increases since identified events may include several rainless periods.

By absence of a widely accepted criterion in literature, a set of criteria has been chosen to identify rain events in the current study, i.e. to mark the start and end time of events. The applied criteria are a minimum event depth of $1.0 \mathrm{~mm}$ and a minimum inter-event time (MIT) of $30 \mathrm{~min}$ that is if the length of a dry period between two gauge rainfall records exceeds 30 min then these records will be identified as part of separate events otherwise these records form a single event. These small MIT values are chosen considering the highly convective nature of the rainfall in the study area and following Balme et al. (2006) and Cosgrove and Garstang (1995). According to Brown et al. (1985), rain events identified by such criteria can be termed "primitive" events and are based on the simplest and most logical approach without the use of additional information regarding the synoptic weather condition such as cloudiness.

The rain event properties that are analyzed in the present study include event depth, event duration, mean event rain rate, peak rain rate of an event and inter-event time (IET) which is defined as the length of the dry period between two consecutive events. Note that IET is always longer than MIT. These event properties are selected since they are considered to be relevant to hydrologic studies. The reader is referred to Dunkerley $(2008 \mathrm{a}, \mathrm{b})$ for further discussion on importance of these event properties in hydrologic studies.

We note that the rain gauges (Hobo S-RGA-M002) used in this study have a funnel diameter of $15.4 \mathrm{~cm}$, a tipping bucket mechanism with a resolution of $0.2 \mathrm{~mm}$, and a measurement range of $0-10 \mathrm{~cm} \mathrm{~h}^{-1}$. The gauges are mounted approximately $1.75 \mathrm{~m}$ above ground surface at open spaces (no trees or buildings) of primary schools and meteorological observation sites operated by the National Meteorological Agency of Ethiopia.

In this study the following definitions apply:

Event depth $\left(d_{\mathrm{e}}\right)$ is:

$d_{\mathrm{e}}=\sum_{i=1}^{T_{\mathrm{e}}} I_{i}$ where $T_{\mathrm{e}}$ is event duration while $I_{i}$ is 1-min rainfall depth at the $i$-th minute since the start time of the rain event.

Mean event rain rate $\left(R_{\mathrm{e}}\right)$ is:

$R_{\mathrm{e}}=\frac{d_{\mathrm{e}}}{T_{\mathrm{e}}}$

where the terms are as defined previously.

Peak rain rate $\left(R_{t, \max }\right)$ for an aggregation scale of $t$ minutes is:

$R_{t, \max }=\max _{1 \leq t \leq E_{\mathrm{d}}}\left(\frac{60}{t} I_{t}\right)$

where max indicates the maximum while the constant 60 is applied to convert $t$-minute rainfall depth to hourly rain rate. The remaining terms are as defined previously.

Relations between various event properties are evaluated through Pearson's product-moment correlation while the variability of event properties is assessed through standard deviation and coefficient of variation $(\mathrm{CV})$ which is the ratio of standard deviation and mean. The effect of terrain elevation on event properties is also evaluated. In addition, we assessed the effects of changing MIT from $30 \mathrm{~min}$ to $8 \mathrm{~h}$ and using two rainfall aggregation time scales $(t)$ of $1 \mathrm{~min}$ and $6 \mathrm{~min}$ on the derived rain event properties.

\section{Results}

\subsection{Rain event properties}

In this section, the rain event properties of Jema station are analysed. Jema station is selected since this rain gauge recorded rainfall data for two consecutive wet seasons that are in JJA of 2007 and 2008. Also, the station is located in between the mountain areas of Gilgel Abbay watershed and Lake Tana and therefore, following the work in Haile et al. (2009) rain event properties at these gauging stations are, presumably, affected by orography and the presence of the lake. Based on the $t=1 \mathrm{~min}$ aggregation scale and a MIT of $30 \mathrm{~min}$, a total of 241 rain events have been observed at Jema with 127 events in JJA 2007 and 114 events in JJA 2008.

Table 1 shows the statistics of rain events at Jema station. A maximum event depth of $67.6 \mathrm{~mm}$ has been recorded in the two seasons. This event depth is 12 times higher than the median of the observed event depths which is only $5.5 \mathrm{~mm}$ indicating that this event can be considered an extreme event. In terms of event duration, a single event has lasted up to $344 \mathrm{~min}$, i.e. about $5.7 \mathrm{~h}$. However, the median of the duration of rain events is only about $1 \mathrm{~h}$ which is approximately 6 times shorter than the maximum duration.

The maximum 1-min peak rain rate at Jema is $180 \mathrm{~mm} \mathrm{~h}^{-1}$ which is equivalent to 15 bucket tips per minute. In terms of median, the peak rain rate is $36 \mathrm{~mm} \mathrm{~h}^{-1}$ which is equivalent to 3 bucket tips per minute. Mean event rain rates range between $0.77 \mathrm{~mm} \mathrm{~h}^{-1}$ and $54.67 \mathrm{~mm} \mathrm{~h}^{-1}$ with a median of $5.90 \mathrm{~mm} \mathrm{~h}^{-1}$. The median of peak rain rate is about 6 
Table 1. Statistics of rain events at Jema in two wet seasons that are JJA of the years 2007 and 2008.

\begin{tabular}{lcrrrr}
\hline Statistics & $\begin{array}{r}\text { Depth } \\
(\mathrm{mm})\end{array}$ & $\begin{array}{r}\text { Duration } \\
(\mathrm{min})\end{array}$ & $\begin{array}{r}\text { Peak rate } \\
\left(\mathrm{mm} \mathrm{h}^{-1}\right)\end{array}$ & $\begin{array}{r}\text { Event rain rate } \\
\left(\mathrm{mm} \mathrm{h}^{-1}\right)\end{array}$ & $\begin{array}{r}\text { Inter-event } \\
\text { time }(\mathrm{min})\end{array}$ \\
\hline Minimum & 1.20 & 3.00 & 12.00 & 0.77 & 33 \\
Maximum & 67.6 & 344.00 & 180.00 & 54.67 & 5677 \\
Mean & 8.91 & 77.60 & 42.56 & 9.72 & 1026 \\
Median & 5.50 & 60.50 & 36.00 & 5.90 & 744 \\
Std. Dev. & 9.84 & 66.09 & 35.45 & 10.35 & 1017 \\
\hline
\end{tabular}

times that of mean event rain rate indicating large differences which is partly explained by inclusion of several rainless periods in a single rain event that results in low mean event rain rate.

The median of IET is $744 \mathrm{~min}$ (i.e. $12.40 \mathrm{~h}$ ) and is 25 times the specified MIT of $30 \mathrm{~min}$. In terms of median, the IET at Jema is about 12 times the median of rain event duration (60.5 $\mathrm{min}$ ) indicating that relatively long dry periods prevail at this station. The median value of IET also suggests that daily rainfall depths at Jema mostly are caused by one or two rain events. It is noted that presence of multiple events in a day restricts applicability of daily rainfall records for event based analysis. As such, rainfall needs to be recorded at subdaily time scales for such analysis at Jema.

\subsection{Relation between rain event properties}

Relations between rain event properties (for MIT $=30 \mathrm{~min}$ ) have been evaluated for rainfall records of Jema station for two consecutive wet seasons. The lower triangle of the correlation matrix of rain event properties is presented in Table 2. The event rain depth is positively correlated to all of the remaining properties. It equally (and moderately) correlates to event duration and mean rain rate. Event depth has strongest correlation with peak rain rate which suggests that events of large rainfall depth contain outbursts of high intensities. As it is suggested by the negative correlation between rain event duration and mean event rain rate, events with short duration have relatively high event rain rate. Lower event rates can be caused partly when events have longer rainless periods as the event duration increases. Overall, the event rain rate at Jema is more related to peak rain rate than to event duration. The IET at Jema has a weak relation to the other rain event properties.

\subsection{Temporal variation of rain event properties}

To evaluate intra-season variability, the rain event properties at Jema have been analysed for each of the three months of the wet seasons of 2007 and 2008. Table 3 shows the median of rain event properties (for MIT $=30 \mathrm{~min}$ ) for each of the three months. It is noted that June is at the beginning of the wet season while August is towards the end. In terms of
Table 2. Lower triangle of correlation matrix between the properties of the selected rainfall events at Jema. The events are observed in two wet seasons that are JJA 2007 and 2008.

\begin{tabular}{lcclcc}
\hline & Depth & Duration & $\begin{array}{l}\text { Event } \\
\text { rain } \\
\text { rate }\end{array}$ & Peak $I_{1}$ & $\begin{array}{c}\text { Inter-event } \\
\text { time }\end{array}$ \\
\hline Depth & 1.000 & & & & \\
Duration & $0.446(*)$ & 1.000 & & & \\
Event rain rate & $0.481(*)$ & $-0.313(*)$ & 1.000 & & \\
Peak $I_{1}$ & $0.739(*)$ & 0.028 & $0.800(*)$ & 1.000 & 1.000 \\
Inter-event time & 0.059 & 0.046 & 0.087 & 0.067 & 1.000 \\
\hline
\end{tabular}

* Correlation is significant at the 0.01 level (2-tailed).

Table 3. The temporal variation of the median of rain event properties at Jema for MIT $=30 \mathrm{~min}$. The events are observed in two wet seasons that are JJA 2007 and 2008.

\begin{tabular}{lcccll}
\hline Statistics & $\begin{array}{c}\text { Depth } \\
(\mathrm{mm})\end{array}$ & $\begin{array}{c}\text { Duration } \\
(\mathrm{min})\end{array}$ & $\begin{array}{c}\text { Peak rate, } \\
I_{1}\left(\mathrm{~mm} \mathrm{~h}^{-1}\right)\end{array}$ & $\begin{array}{l}\text { Event rain } \\
\text { rate } \\
\left(\mathrm{mm} \mathrm{h}^{-1}\right)\end{array}$ & $\begin{array}{l}\text { Inter- } \\
\text { event } \\
\text { time (h) }\end{array}$ \\
\hline \multicolumn{5}{c}{ Median } \\
\hline June & 6.6 & 64.0 & 36 & 6.52 & 17.6 \\
July & 4.7 & 55.5 & 24 & 6.11 & 11.33 \\
August & 5.4 & 61.0 & 36 & 6 & 13.56 \\
\hline \multicolumn{7}{c}{$\mathrm{CV}$} \\
\hline June & 0.998 & 0.773 & 0.824 & 1.002 & 0.882 \\
July & 1.161 & 0.905 & 0.860 & 1.030 & 0.928 \\
August & 1.020 & 0.931 & 0.797 & 1.093 & 1.024 \\
\hline
\end{tabular}

the median of rain event depth, there are some differences between the events in June, July and August. June has the highest rain event depth while July has the lowest event depth with a $2 \mathrm{~mm}$ difference between the event depths of the two months.

In terms of the median value, the rain events in July have the shortest duration while the events in June have the longest duration. The June events have durations that on average are 8.5 min longer than those of the July events. In terms of peak rain rate, the events in July have the lowest rain rate indicating that outbursts of high intensities are less common in mid-season events. In terms of event rain rate, the events in August have the lowest rain rate while those in June have the highest rain rate. Also, the July events have the shortest IET which suggests that these rain events are likely to be more clustered in time than those in June and August. We note that there is a $6.3 \mathrm{~h}$ difference between the median values of IETs of the events of June and July. Overall, events at the start and towards the end of the wet season have somewhat similar properties while events in the mid-season differ in this respect. At the start and towards the end of the wet season, rain events have larger depth and longer duration and IET compared to events in the mid-season. 
The coefficient of variation (CV) in Table 3 indicates that the rain event depth in July is more variable in time than that of June and August. Also, there is some difference in terms of variability of rain event duration in each of the months. The event duration in June shows the least variation in time compared to the events of the other months of the wet season. In addition, Table 3 shows that peak rain rate of the events in August is the least variable while the difference in $\mathrm{CV}$ of mean event rain rate of the three months is less than $10 \%$. In terms of IET, the largest variability has been observed in August. Overall, the mid-season events have depth, duration and peak rain rate that are more variable compared to events at the start and end of the wet season.

\subsection{Spatial variation of rain event properties}

In this section, the spatial variation of rain event properties is analysed based on rainfall records from 8 stations. The number of rain events based on MIT $=30 \mathrm{~min}$ is $122,100,140$, 112, 177, 122, 105, and 153 for Addis Kidam, Bahir Dar, Dangila, Durbet, Injibara, Jema, Koga and Sekela, respectively. The largest number of events is observed at Sekela and Injibara which are situated on mountain areas while the smallest number of events is observed at Bahir Dar which is at the south shore of Lake Tana. Haile et al. (2010a) show that rainfall at Sekela is largely important for runoff modelling of the Gilgel Abbay watershed. The results in the present study suggest that one of the reasons for the importance of this station could be due to the relatively large number of rain events that are observed as compared to the other stations.

\subsubsection{Rain event depth}

Statistical properties of rain event depths of the eight stations (for JJA 2007) are presented in Fig. 2. The 25\% and the 75\% quartiles are shown by the bottom and top edges of the box, respectively while the median is shown by the horizontal line inside the box. The top and bottom horizontal bars represent the $25 \%$ quartile minus $1.5 \mathrm{IQR}$ and the $75 \%$ quartile plus 1.5 IQR, respectively. IQR is defined as the interquartile range which is the $75 \%$ quartile minus the $25 \%$ quartile and is defined by the vertical size of the box.

By the Box-whisker plot in Fig. 2 some suggestions can be made with respect to rain event depth in the basin. Overall, rain event depths have skewed distribution where event depths higher than the median value are distributed over a larger range than event depths that are lower than the median. In terms of median, Addis Kidam, Dangila, Injibara and Sekela stations which are situated on mountain areas have events with lowest rainfall depths as compared to those of lowland stations. The lowest event depth is $3.4 \mathrm{~mm}$ at Injibara which is located on a mountain area while the highest depth is $5.0 \mathrm{~mm}$ at Jema which is situated at an intermediate location in between the mountain areas and lowland areas

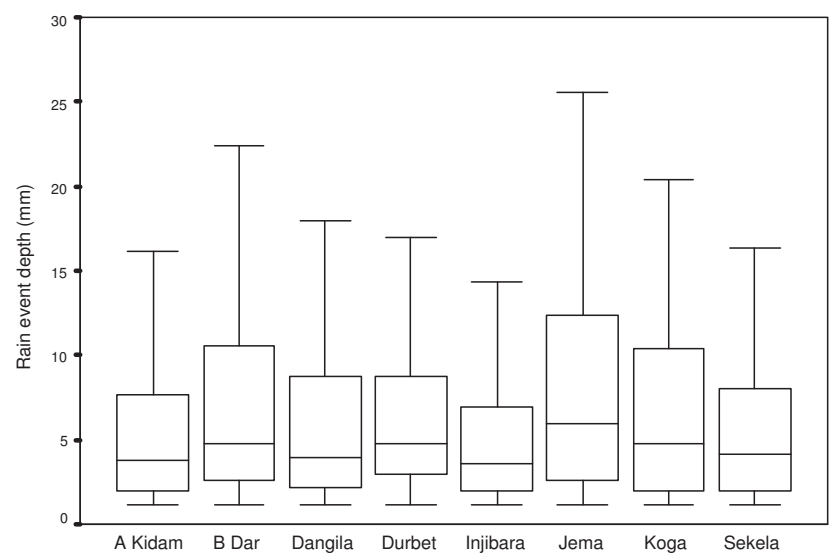

Fig. 2. Box-whisker plot of the rain event depths in JJA of 2007 as observed at eight rain gauge stations. The lower and the upper bars indicate the $25 \%$ quartile minus $1.5 \mathrm{IQR}$ and the $75 \%$ quartile plus 1.5 IQR, respectively. IQR refers to the interquartile range which is defined by the height of the box. The bar inside the boxes shows the median while the upper and lower edges of the boxes show the $75 \%$ and the $25 \%$ quartiles.

near Lake Tana. On average, Jema receives an event depth of 1.47 times that of Injibara indicating significant spatial variation of event depth in the study area. Bahir Dar which is on the south shore of the lake has a median event depth of $4.8 \mathrm{~mm}$.

The stations that are relatively close to the lake (Bahir Dar, Koga and Jema) have the lowest terrain elevation and have largest IQRs. This suggests that these stations have event depths with larger variability compared to stations in the mountain areas. Such results imply that the variability of event depth decreases by the combined effect of an increase in distance from the lake and an increase in terrain elevation. The Box-whisker plot also shows that the $75 \%$ quartiles of event depths of stations near the lake are larger than event depths in the mountain areas. Injibara station which is situated on a mountain area has the smallest $25 \%$ quartile of event depth.

\subsubsection{Rain event duration}

Figure 3 shows a Box-whisker plot of rain event duration for all eight stations. Similar to rain event depth, some suggestions can be made regarding spatial variation of rain event duration. Overall, the distribution of event duration is skewed since events that have longer durations than the median value are distributed over a larger range than event durations that are shorter than the median. However, the skewness is less pronounced compared to the skewed distribution of rain event depth and implies that the mean event duration in the study area is less affected by extreme values as compared to event depth. 


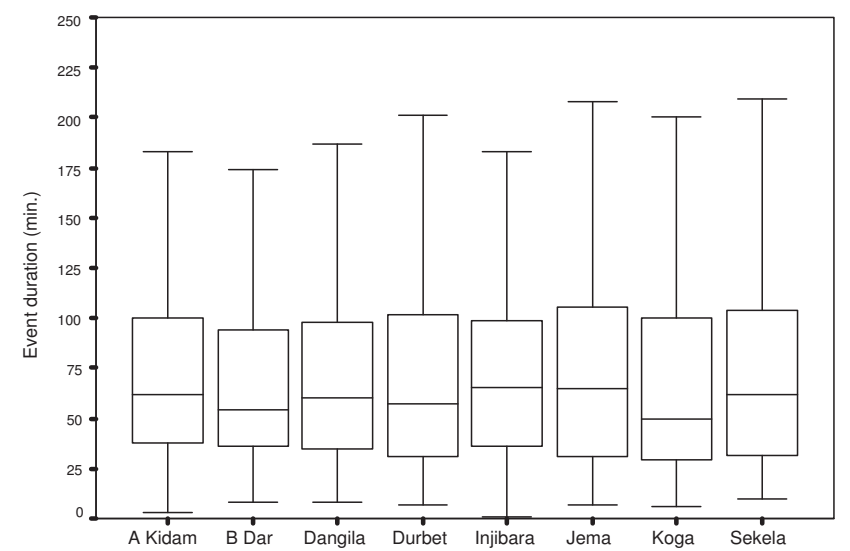

Fig. 3. Box-whisker plot of the rain event durations in JJA of 2007 as observed at eight rain gauge stations.

In terms of median, Addis Kidam, Dangila, Injibara and Sekela stations which are situated in mountain areas have events with longest duration as compared to events of the remaining stations that are in the lowland. An exception is Jema which has relatively low elevation but on average has event duration which is comparable to that of the events on mountain areas. Koga and Bahir Dar stations which are at lower elevation and relatively close to the lake have events with the shortest duration on average.

Durbet, Jema and Sekela have larger IQR for event duration than the remaining stations and thus event duration of these stations is more variable. Although the median of the event duration at Sekela and Injibara is comparable, the IQR does not show that event duration is equally variable at these stations. Rain event duration at Sekela is more variable as compared to event duration at Injibara.

\subsubsection{Mean event rain rate}

A Box-whisker plot of mean event rain rates at the eight stations is presented in Fig. 4. Similar to rain event depth, the distribution of mean event rain rate is skewed. In terms of median, the mountain stations Addis Kidam, Dangila, Injibara and Sekela have events with lower rain rate than the stations that are relatively close to the lake. The lowest median value of event rain rate is observed at Injibara $\left(3.5 \mathrm{~mm} \mathrm{~h}^{-1}\right)$ while the highest median value is observed at Jema and Koga (approximately $5.5 \mathrm{~mm} \mathrm{~h}^{-1}$ ). As such, on average the maximum rain rate in the study area is 1.6 times that of the minimum rain rate. Bahir Dar, Koga and Jema also have a relatively large IQR. Results suggest that rainfall of lowland areas and thus close to the lake are characterised by larger variability and higher event depth as compared to that of mountain areas. Clear reasoning on the causes is not trivial particularly since assessments of diurnal cycle properties (see Haile et al., 2009) indicate that rainfall close to Lake Tana commonly is at late evening hours (22:00-24:00 LST)

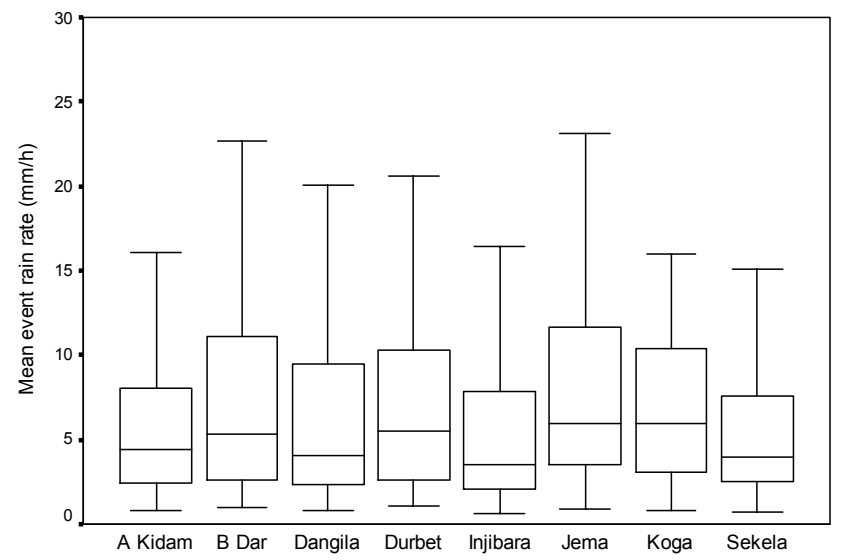

Fig. 4. Box-whisker plot of mean event rain rate in JJA of 2007 as observed at eight rain gauge stations.

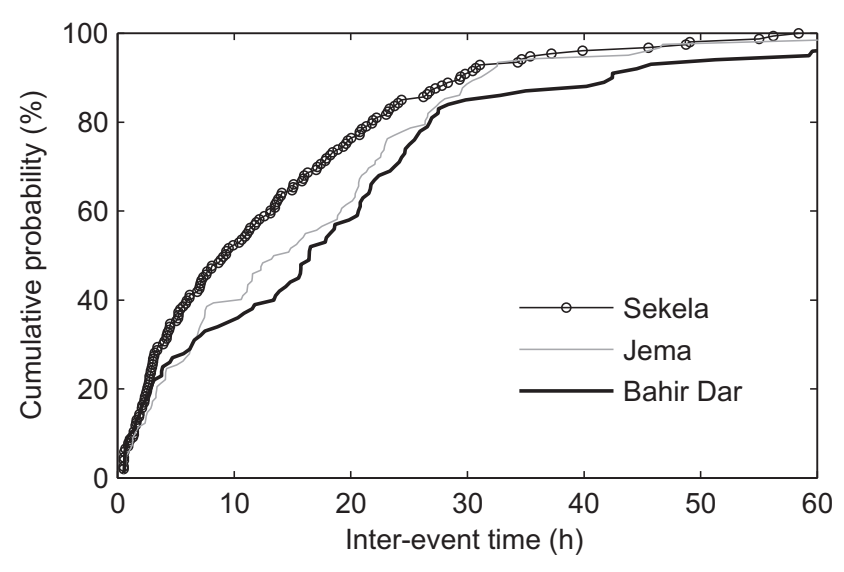

Fig. 5. Cumulative probability of inter-event time in JJA of 2007 as observed at three rain gauge stations.

while rainfall in the mountain ranges commonly is at late afternoon hours (15:00-18:00 LST) and early morning hours (03:00-06:00 LST).

The $75 \%$ quartiles of rain event rates at the stations which are located near the lake are higher than rates in the mountain areas. Injibara which is located on the mountain area has the lowest $25 \%$ quartile of event rates from the network. Over all, the Box-whisker plots of event rates have comparable spatial pattern to that of rain event depths suggesting some relation between these two event properties. We note that such relation is also suggested by the correlation matrix in Table 2.

\subsubsection{Inter-event time}

Figure 5 shows the cumulative probability distribution of inter-event times at three stations. Results show that the $10 \%$ quantile inter-event time is $1.4 \mathrm{~h}, 1.5 \mathrm{~h}$ and $1.0 \mathrm{~h}$ at Sekela, Jema and Bahir Dar, respectively. The median interevent time is $9.0 \mathrm{~h}, 13.5 \mathrm{~h}$ and $16.5 \mathrm{~h}$ while the $90 \%$ quantile 
inter-event time is $29.5 \mathrm{~h}, 31 \mathrm{~h}$ and $42.5 \mathrm{~h}$ at Sekela, Jema and Bahir Dar, respectively.

At any selected cumulative probability, Sekela has the shortest IET while Bahir Dar has the longest IET. Results reveal that, on average, the lowland areas near Bahir Dar have a dry period length of 1.8 times that of the mountain areas near Sekela. Jema which is situated at an intermediate distance between the high mountain areas and the lake has an IET which is shorter than that of Bahir Dar but longer than that of Sekela. Results of IET thus suggest that rainfall events are more frequent in the mountain areas as compared to the lower elevated areas close to the lake. We note that assessment of the diurnal variation of convective index (CI) by use of satellite based rainfall data in Haile et al. (2009) indicated a similar pattern.

\subsubsection{Relation between elevation and event properties}

In previous sub-sections, it is shown that event properties of the study area have some relation with terrain elevation and possibly distance to Lake Tana. To assess how elevation may affect rain event properties (MIT $=30 \mathrm{~min}$ ) a regression analysis is performed following Dairaku et al. (2004). In the present study, a non-linear regression analysis is selected since it showed a small improvement in the coefficient of determination $\left(R^{2}\right)$ value as compared to linear regression.

The regression equations that are based on data from 8 stations are presented in Table 4 and the 10\%, 50\% and 90\% quantiles of the event properties are selected to consider low, normal and high values of event properties, respectively. The $R^{2}$ value in Table 4 shows that terrain elevation weakly explains the variation in the $10 \%$ quantile event depth. However, the $50 \%$ and the $90 \%$ quantiles of event depth are much more strongly related to terrain elevation. The results suggest that normal and large event depths in the study area are affected by elevation. In terms of event duration, the $10 \%$ quantile is very weakly related to terrain elevation while the $90 \%$ quantile is much more strongly related with highest $R^{2}$ value. Results indicate that events of short duration are not directly affected by elevation but when event duration increases, such may be due to effects of elevation.

The $R^{2}$ value indicates that variations in the three quantiles of mean event rain rate may be related to variation in terrain elevation. The lowland areas in the study area receive relatively high rain rate as compared to the mountain areas. However, in terms of peak event rain rate, a relation could not be established between the $10 \%$ and the $50 \%$ quantiles with terrain elevation since quantiles of peak rain rate are found to be equal at all 8 stations. However, the $90 \%$ peak rain rate is related to terrain elevation and the slope of the regression equation suggests that events in lowland areas can be characterized by high peak rain rates. Although the $10 \%$ quantile of IET is weakly related to terrain elevation, the $50 \%$ and the $90 \%$ quantiles of IET are related to terrain elevation with a very high correlation for the $50 \%$ quantile. Overall, higher
Table 4. Relation between rain event properties and terrain elevation (Elev.).

\begin{tabular}{|c|c|c|}
\hline & Equation & $R^{2}$ \\
\hline \multicolumn{3}{|c|}{ Event depth } \\
\hline $10 \%$ Quantile & -0.0002 Elev. +1.8730 & 0.1527 \\
\hline Median & 2007.1 Elev. $^{-0.7954}$ & 0.4915 \\
\hline 90\% Quantile & 14311 Elev. $^{-0.8796}$ & 0.5161 \\
\hline \multicolumn{3}{|c|}{ Event duration } \\
\hline $10 \%$ Quantile & 11.629 Elev. $^{0.0546}$ & 0.0042 \\
\hline Median & 3.4611 Elev. $^{0.3694}$ & 0.3312 \\
\hline 90\% Quantile & 4986.8 Elev. $^{-0.4521}$ & 0.5248 \\
\hline \multicolumn{3}{|c|}{ Mean event rain rate } \\
\hline $10 \%$ Quantile & 648.84 Elev. $^{-0.7763}$ & 0.5628 \\
\hline Median & 34407 Elev. $^{-1.1559}$ & 0.6819 \\
\hline 90\% Quantile & 459710 Elev. $^{-1.3301}$ & 0.6755 \\
\hline \multicolumn{3}{|c|}{ Peak event rain rate } \\
\hline $10 \%$ Quantile & - & - \\
\hline Median & - & - \\
\hline 90\% Quantile & -0.0327 Elev. +154.41 & 0.4884 \\
\hline \multicolumn{3}{|c|}{ Inter-event time } \\
\hline $10 \%$ Quantile & 0.0169 Elev. $^{0.5509}$ & 0.0732 \\
\hline Median & 3611447 Elev. $^{-1.64}$ & 0.9100 \\
\hline 90\% Quantile & 259888 Elev. $^{-1.1659}$ & 0.5666 \\
\hline
\end{tabular}

quantiles of event properties are affected by elevation while low quantiles of event properties only are weakly affected with the exception of event rain rate.

Figure 6 shows the relation between event properties and terrain elevation. The median of event properties is selected to evaluate the relation while the regression equations are presented in Table 4. Figure 6 shows that rain event depth, mean event rain rate and IET decrease with an increase in terrain elevation while event duration increases with an increase in terrain elevation. As such, mountain areas receive rainfall of relatively small depth, low rain rate, long duration and short IET. Haile et al. (2009, 2010a) showed that the mountain areas of Lake Tana basin receive relatively large seasonal rainfall depth. The result of the present study showed that the large seasonal rainfall of the mountain areas is mainly due to frequent events of relatively long duration. However, the seasonal rainfall of lowland areas is largely affected by events with high intensity but short duration.

\subsection{Effect of changing the criteria for event definition}

Analyses in previous sections are performed for a MIT of 30 min. Dunkerley (2008b) indicated that MIT commonly 
(a)

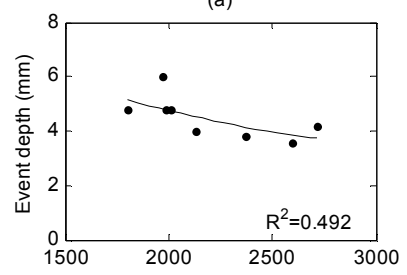

(c)

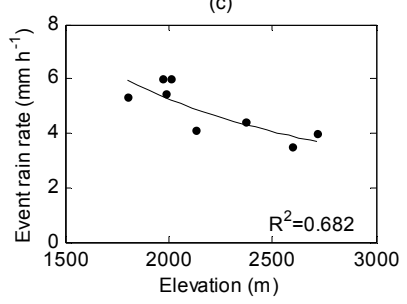

(b)

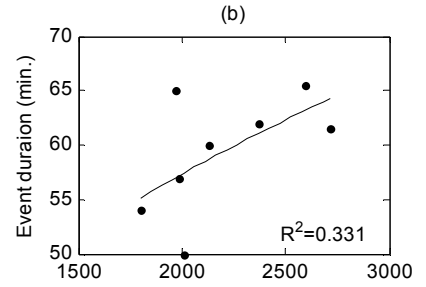

(d)

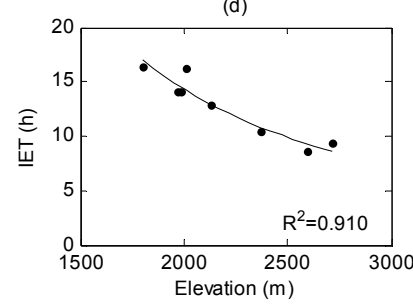

Fig. 6. Relation between event properties and terrain elevation. The event properties are (a) event depth, (b) event duration, (c) event intensity and (d) inter-event time (IET). The median of each of the event properties is selected for the regression and the regression equations are shown in Table 4.

ranges between $3 \mathrm{~min}$ and $24 \mathrm{~h}$ and often MIT of 6 and $8 \mathrm{~h}$ is selected (for MIT $=8 \mathrm{~h}$; see Asdak et al., 1998; Aryal et al., 2007). We selected MIT $=30 \mathrm{~min}$ by considering that the duration of most events in the study area is in the order of $1 \mathrm{~h} \pm 10 \mathrm{~min}$ and by considering the work of Haile et al. $(2009,2010 \mathrm{c})$ who showed that rainfall in this basin primarily is of convective nature. Changing the IET, however, affects the analyses results of rain event properties since larger IETs directly result in a lower number of events that must be of longer duration. As such, selection of IET is a critical step. From a hydrological point of view and particularly when catchment sizes increase from local to regional and larger scales, it may be necessary to select a longer MIT than was used in the present study. Selection of a large MIT allows achieving more hydrologic independency between two successive events but events that have longer duration and rainless periods that are smaller than a specified MIT are ignored. To assess the effect of increasing MIT in the study area we calculated event properties for MIT $=8 \mathrm{~h}$. Results of all eight stations are compared to results of MIT of $30 \mathrm{~min}$ and percent changes in the event properties are related to elevation (see Fig. 7).

Changing MIT from $30 \mathrm{~min}$ to $8 \mathrm{~h}$ resulted in a minimum reduction of number of events by $37-61 \%$. This significant reduction indicates that inclusion of several rainless periods by using a longer MIT significantly reduces the number of events. The change in the number of events is strongly related $\left(R^{2}=0.785\right)$ to terrain elevation with the largest effect observed for highland stations. These stations are characterised by high rainfall intermittency as compared to the lowland stations in Lake Tana basin (see Haile et al., 2009). Event depth increased significantly (91 to 182\%) with an
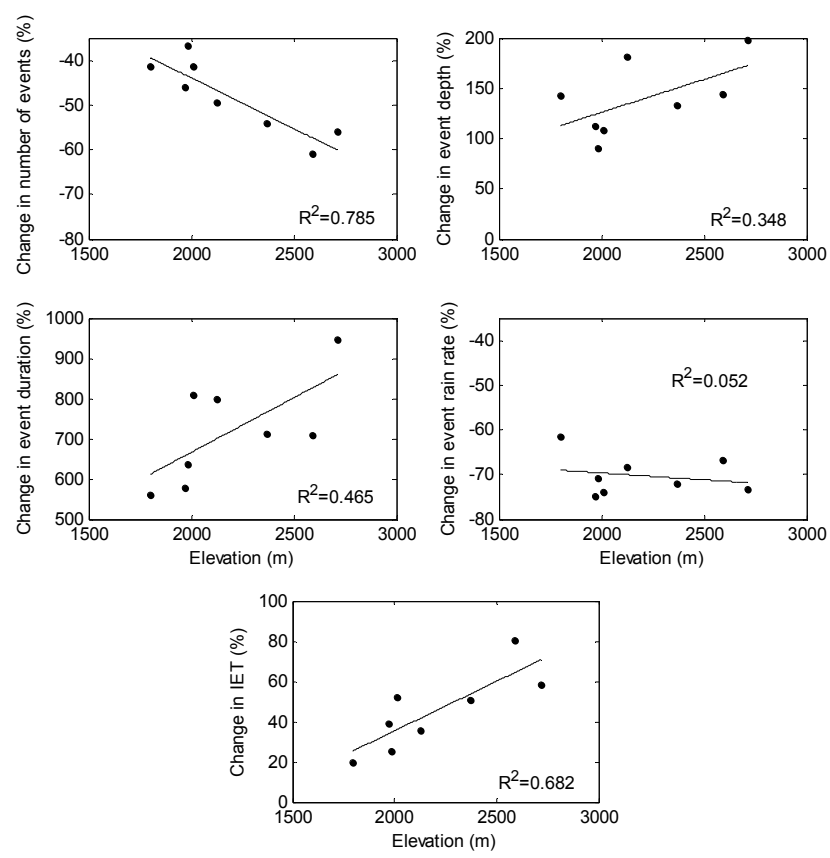

Fig. 7. Percent changes in the event properties by changing the minimum inter-event time (MIT) from $30 \mathrm{~min}$ to $8 \mathrm{~h}$. Results are plotted against the terrain elevation of all eight gauge stations.

increase in MIT. This change in event depth is only moderately related $\left(R^{2}=0.348\right)$ to terrain elevation. Increasing MIT resulted in the largest effect on event duration which decreased by 559 to $807 \%$. The effect of MIT on event duration moderately varies with terrain elevation $\left(R^{2}=0.465\right)$ with the largest effect being observed for highland stations. The event rain rate decreased (by $61-75 \%$ ) when we changed the MIT from $30 \mathrm{~min}$ to $8 \mathrm{~h}$. However, the change in event rain rate is weakly related to terrain elevation $\left(R^{2}=0.052\right)$. This could be caused by the moderate relation of event duration and event depth to terrain elevation. IET changed by 19 $80 \%$ with IET of highland stations being strongly affected by MIT values $\left(R^{2}=0.682\right)$. Overall, these results show that the specified MIT has a strong impact on the estimated values of event properties. Such impact on event properties varies spatially with terrain elevation.

We assessed the relation between terrain elevation and event properties that are identified using MIT $=8 \mathrm{~h}$ (Fig. 8) that may be considered relatively long for the study area. Results indicate that event depth has very weak relation to elevation $\left(R^{2}=0.019\right)$ while event duration, rain rate and IET have medium to strong relation to terrain elevation with $R^{2}=0.819,0.895$ and 0.552 respectively. Event duration increased with terrain elevation while rain rate and IET decreased with an increase in elevation suggesting that events of highland areas have longer duration, relatively low rain rate and longer dry periods between events than events in lowland areas (see Table 5). 

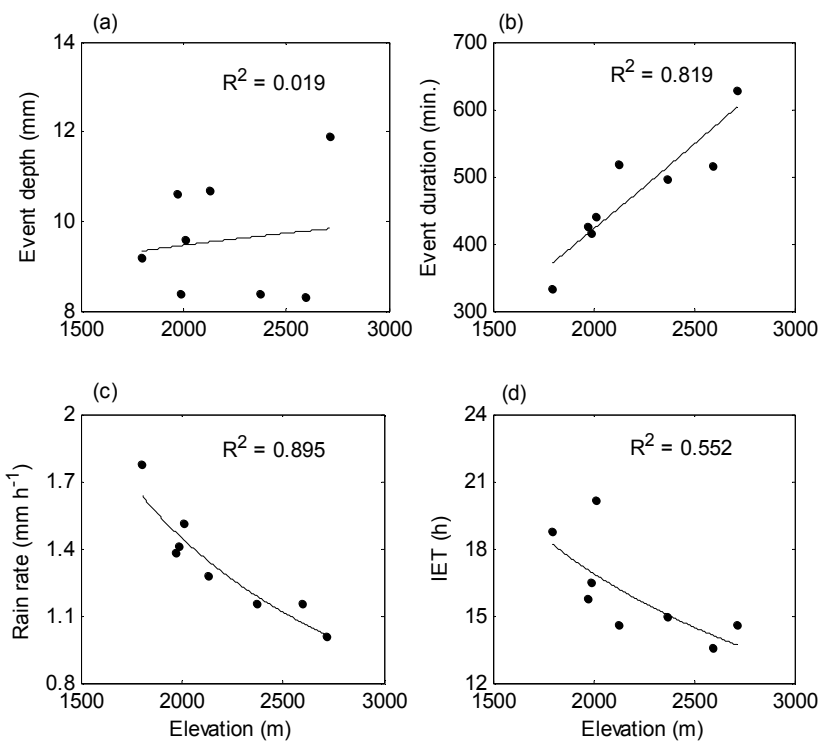

Fig. 8. Relation between event properties and terrain elevation (MIT $=8 \mathrm{~h}$ ). The median of each of the event properties is selected for the regression and the regression equations are presented in Table 5 .

\subsection{Effect of temporal aggregation of rainfall data on event properties}

In tipping bucket gauges, rainfall amounts are measured by the number of tips where each tip represents a fixed rainfall depth. Rain event properties such as rain rates are defined by aggregating the number of tips over selected aggregation period (e.g. $1 \mathrm{~min}, 1 \mathrm{~h}$ or longer). Aggregating rainfall data over a long period may result in inclusion of several rainless gaps which might affect the value of estimated rain event properties. We note that measurement errors are commonly large when data is aggregated over a small time period (e.g. $1 \mathrm{~min}$ ) while these errors may diminish for a long time period (see Habib et al., 2001 for further discussion on gauge sampling errors). In the present study, we aggregated the raw rainfall data into 1-min time periods. Given that each gauge tip in the present study represents $0.2 \mathrm{~mm}$, this suggests that the maximum error of the 1 -min rain rate is $12 \mathrm{~mm} \mathrm{~h}^{-1}$ when upscaled to $1 \mathrm{~h}$. We presume that uncertainty increases when the length of the aggregation period decreases since rainfall intensities are highest and rainless periods are smallest for short time intervals. Therefore it is desirable to understand how temporal aggregation of rainfall data affects the estimated event properties.

We assessed the effect of aggregation by aggregating the rainfall data of Jema (2007 and 2008) to $6 \mathrm{~min}$ and $1 \mathrm{~min}$. We note that the selection of $6 \mathrm{~min}$ is somewhat arbitrary but, presumably, when choosing much larger values rainfall events of non-convective nature are more suitable. For $\mathrm{MIT}=30 \mathrm{~min}$, the increase in aggregation period (from $1 \mathrm{~min}$
Table 5. Regression equations that relate median of rain event properties $(\mathrm{MIT}=8 \mathrm{~h})$ to terrain elevation.

\begin{tabular}{llc}
\hline Event property & Equation & $R^{2}$ \\
\hline Event depth & 3.6142 Elv. ${ }^{0.1266}$ & 0.019 \\
Event duration & 0.0543 Elv. ${ }^{1.1781}$ & 0.819 \\
Rain rate & 10105 Elv. $^{-1.1642}$ & 0.895 \\
IET & 3182.4 Elv. $^{-0.689}$ & 0.552 \\
\hline
\end{tabular}

to $6 \mathrm{~min}$ ) caused a slight decrease of number of events (by $1.2 \%)$ and an increase of the median of event depth (1.8\%). It resulted in a large change in peak rain rate $(-19 \%)$, event rain rate $(-19.5 \%)$, duration $(19.0 \%)$ and IET $(4.9 \%)$. When using MIT $=8 \mathrm{~h}$, aggregation over $6 \mathrm{~min}$ instead of $1 \mathrm{~min}$ changed values of event properties only slightly. The number of events decreased by $0.7 \%$ while event depth, rain rate, duration and IET increased by $1.3 \%, 1.4 \%, 0.7 \%$ and $0.45 \%$, respectively.

\section{Discussion and conclusion}

The objective in this study is to understand the properties of rain events in the source basin of the Upper Blue Nile River and to evaluate how rain event properties are affected by terrain elevation in the basin. Since this study is based on rainfall data from a recently installed network of experimental gauges, our analysis are based on a relatively short period of 2 years.

Temporal characteristics of rain event properties are analyzed to evaluate how event properties change with time. Also, relations between various rain event properties are evaluated to enhance our understanding of rainfall and to provide information that may be useful for generation of synthetic rainfall data. The considered event properties are rain event depth, duration, mean rain rate, peak rain rate and interevent time (IET).

The relation between various rain event properties is evaluated through correlation analysis. Results indicate that rain event depth increases with an increase in event duration, mean event rain rate, and peak rain rate. Rain event depth in the study area is more related to peak intensity than to event duration. As such events with large rain depth contain outbursts of high rain intensities. Analyses in this study show that IET has a weak relation with the other rain event properties.

We found that at the start and towards the end of the wet season, rain event depth is relatively large with relatively long event duration and long IET. Such results indicate that two consecutive events as observed in early and late season are separated by longer dry periods than events in the midseason. In terms of median, the June events have an event 
depth that is $2 \mathrm{~mm}$ higher and events have duration that is 8.5 min longer than the July events. The IET in June on average is $6.3 \mathrm{~h}$ longer than in July. Also, mid-season events have depth, duration and peak intensity that are more variable as compared to the events at the start and at the end of the wet season. Such differences may affect hydrologic processes as, for instance, longer IET may cause larger evapotranspiration between two consecutive rain events thus affecting infiltration volumes and possibly runoff production.

Haile et al. (2009) showed that there is a weak relation between seasonal rainfall amount and terrain elevation or distance to the lake although the diurnal cycle of rainfall across the study area is strongly affected by mountain ranges. The results of the present study revealed that terrain elevation of the Lake Tana basin affects rain event properties in particular for the $50 \%, 75 \%$ and $90 \%$ quantiles. The interquartile range shows that the variability of event depth and mean event rain rate decreases with an increase in terrain elevation that is observed at increasing distances from the lake. As such, event depths and rain rates at lowland areas in the study area near the lake shore show larger variability as compared to events in mountain areas of the basin.

Values of the coefficient of determination $\left(R^{2}\right)$ indicate that terrain elevation weakly relates to the $10 \%$ quantile of event depth, event duration, peak rain rate, and IET. This suggests that events with small values of properties such as rainfall depth are not affected by terrain elevation. In terms of the median values, the maximum spatial difference in the watershed is $2.4 \mathrm{~mm}, 2.5 \mathrm{~mm} \mathrm{~h}^{-1}, 15.5 \mathrm{~min}$ and $7.85 \mathrm{~h}$ for event depth, mean event rain rate, event duration, IET, respectively. The median of event durations in the watershed is in the range of $1 \mathrm{~h} \pm 10 \mathrm{~min}$. These characteristics reveal that the rain events in the study area have relatively short duration which is common for rain events of convective nature.

Many studies report on the effect of elevation on annual, seasonal or daily rainfall but only few studies report how elevation affects rain event properties. In the present study such evaluation is performed for Lake Tana basin. The results revealed that (i) the lowland areas have events with relatively larger variability in rain depth and rain rate as compared to events in the mountain areas, (ii) on average, rain events in lowland areas have larger depth and higher rain rate, are of shorter duration and have longer IET than events in mountain areas; (iii) the spatial distribution of large values of event properties ( $75 \%$ and $90 \%$ quantiles of event depth, duration, rain rate) are affected by terrain elevation; (iv) the spatial distribution of small values of event properties (10\% quantiles) except that of mean event rain rate are weakly related to terrain elevation. These results are similar to results by Barros et al. (2000) who also indicated that the lower-elevation stations received higher rain rate rainfall over short durations. We note that in Barros et al. (2000) only 4 month of data was used for an area in Nepal. Our results are somewhat in contrast to those by Dairaku et al. (2004) who showed that relatively low intensity events in the mountains of north-western
Thailand are weakly affected by terrain elevation. We presume that such difference can be caused by climatic factors at continental scale but also by local climatic factors in our study area by the presence of Lake Tana. In Haile et al. (2009) it is discussed that Lake Tana may act as a major source of evaporative water that affects the diurnal rainfall cycle across the Gilgel Abbay watershed.

For rain events that are identified using $\mathrm{MIT}=30 \mathrm{~min}$, peak rain rate, event rain rate and duration are the most affected event properties when rainfall data is aggregated over $6 \mathrm{~min}$ as compared to a $1 \mathrm{~min}$ period. The values of these event properties changed by about $-19 \%,-19 \%$ and $19 \%$, respectively. The effect of increasing the aggregation time period on all event properties diminished (values changed only by $<1.5 \%$ ) when rain events are identified using $\mathrm{MIT}=8 \mathrm{~h}$.

Results show that the specified MIT has a strong impact on the estimated values of some event properties. Increasing MIT from $30 \mathrm{~min}$ to $8 \mathrm{~h}$ resulted in the largest effect on event duration which decreased by 559 to $807 \%$. The effect of MIT on event duration, event depth and IET is directly related to terrain elevation while the number of events is inversely related. However, there is a weak relation between the changes in event rain rate and terrain elevation. Overall, changing MIT to $8 \mathrm{~h}$ has the largest effect on the mountain stations that are characterised by high rainfall intermittency. Using MIT of $8 \mathrm{~h}$ instead of $30 \mathrm{~min}$ resulted in a weaker relation between elevation and event depth and IET while it resulted in stronger relation between elevation and event duration and rain rate.

Numerous studies showed that rain event properties, in particular rain rate and duration, have significant effect on the extent of water-driven erosion processes. For instance, kinetic energy, which is a commonly used indicator for the ability of rainfall to detach soil particles, is related to rain rate (see van Dijk et al., 2002 for an extensive review). The existence of such relation suggests that variability of rain event properties can lead to variations in kinetic energy in space and time (see Angulo-Martínez et al., 2009). Based on the results of the present study we speculate that rain events of mountain areas of Gilgel Abbay watershed have less soil erosive power (due to relatively small rain rate) than rain events of lowlands of this watershed. We recommend that future studies should evaluate the effect of the observed variability of event properties on spatial variation of soil erosion in the watershed.

Acknowledgements. This study is mainly funded by the Netherlands organization for international cooperation in higher education (Nuffic). Partial support to the first and third authors is provided by the National Science Foundation (NSF); award number OISE-0914618. We kindly thank the reviewers for their constructive remarks that helped us to improve the quality of the manuscript.

Edited by: A. Melesse 


\section{References}

Abdo, K. S., Fiseha, B. M., Rientjes, T. H. M., Gieske, A. S. M., and Haile, A. T.: Assessment of climate change impacts on the hydrology of Gilgel Abay catchment in Lake Tana basin, Ethiopia, Hydrol. Process., 23(6), 3661-3669, 2009.

Angel, J. R., Palecki, M. A., and Hollinger, S. E.: Storm Precipitation in the United States, Part II: soil erosion characteristics, J. Appl. Meteorol., 44, 947-959, 2005.

Angulo-Martínez, M., López-Vicente, M., Vicente-Serrano, S. M., and Beguería, S.: Mapping rainfall erosivity at a regional scale: a comparison of interpolation methods in the Ebro Basin (NE Spain), Hydrol. Earth Syst. Sci., 13, 1907-1920, doi:10.5194/hess-13-1907-2009, 2009.

Arnaud, P., Fine, J. A., and Lavabre, J.: An hourly rainfall generation model applicable to all types of climate, Atmos. Res., 85, 230-242, 2007.

Aryal, R. K., Furumai, H., Nakajima, F., Jinadasa, H. K. P. K.: The role of inter-event time definition and recovery of initial/depression loss for the accuracy in quantitative simulations of highway runoff, Urban Water J., 4, 53-58, 2007.

Asdak, C., Jarvis, P. G., van Gardingen, P., and Fraser, A.: Rainfall interception loss in unlogged and logged forest areas of central Kalimantan, Indonesia, Hydrology, 206, 237-244, 1998.

Balme, M., Vischel, T., Lebel, T., Peugeot, C., and Galle, S.: Assessing the water balance in the Sahel: impact of small scale rainfall variability on runoff, Part 1: rainfall variability analysis, J. Hydrol., 331, 336-348, 2006.

Barros, A. P., Joshi, M., Putkonen, J., and Burbank, D. W.: A study of the 1999 monsoon rainfall in a mountain region in central Nepal using TRMM products and rain gauge observations, Geophys. Res. Lett., 27, 3683-3686, 2000.

Brown, B. G., Katz, R. W., and Murphy, A. H.: Exploratory analysis of precipitation events with implications for stochastic modelling, J. Climate, Appl. Meteorol., 24, 57-67, 1985.

Cosgrove, C. M. and Garstang, M.: Simulation of rain events from rain-gauge measurements, Int. J. Climatol., 15, 1021-1029, 1995.

Dairaku, K., Emori, S., and Oki, T.: Rainfall amount, intensity, duration and frequency relationships in the Mae Chaem watershed in Southeast Asia, J. Hydrometeorol., 5, 458-470, 2004.

de Vos, N. J. and Rientjes, T. H. M.: Multi-objective training of artificial neural networks for rainfall - runoff modeling, Water Resour. Res., 44, W08434, doi:10.1029/2007WR006734, 2008.

Diodato, N. and Bellocchi, G.: Estimating monthly (R)USLE climate input in a Mediterranean region using limited data, J. Hydrol., 345, 224-236, 2007.

Dunkerley, D.: Rain event properties in nature and in rainfall simulation experiments: a comparative review with recommendations for increasingly systematic study and reporting, Hydrol. Process., 22, 4415-4435, 2008a.

Dunkerley, D.: Identifying individual rain events from pluviograph records: a review with analysis of data from an Australian dryland site, Hydrol. Process., 22, 5024-5036, 2008 b.

Habib, E., Krajewski, W. F., and Kruger, A.: Sampling errors of tipping-bucket rain gauge measurements, ASCE J. Hydrol. Eng., 6(2), 159-166, 2001.
Haile, A. T., Rientjes, T., Gieske, M., and Gebremichael, M.: Rainfall Variability over mountainous and adjacent lake areas: the case of Lake Tana basin at the source of the Blue Nile River, J. Appl. Meteorol. Clim., 488, 1696-1717, 2009.

Haile, A. T., Rientjes, T., and Reggiani, P.: Model sensitivity to rainfall representation: the representative elementary watershed model, J. Hydrol., in revision, 2010a.

Haile, A. T., Rientjes, T. H. M., Gieske, A., Jetten, V., and Mekonnen, G.: Satellite remote sensing and conceptual cloud modeling for convective rainfall simulation, Adv. Water Resour., in press, doi:10.1016/j.advwatres.2010.08.007, 2010b.

Haile, A. T., Rientjes, T. H. M., Gieske, A. S. M., and Mekonnen, G.: Multispectral remote sensing for rainfall detection and estimation at the source of the Blue Nile River, Int. J. Appl. Earth Obs. Geoinf., 12(2010), Supplement 1, S76-S82, 2010c.

Koutsoyiannis, D. and Onof, C.: Rainfall disaggregation using adjusting procedures on a poisson cluster model, J. Hydrol., 246, 109-122, 2001.

Kusumastuti, D. I., Struthers, I., Sivapalan, M., and Reynolds, D. A.: Threshold effects in catchment storm response and the occurrence and magnitude of flood events: implications for flood frequency, Hydrol. Earth Syst. Sci., 11, 1515-1528, doi:10.5194/hess-11-1515-2007, 2007.

Loukas, A. and Quick, M. C.: Spatial and temporal distribuition of storm precipitation in southwestern British Columbia, J. Hydrol., 174, 37-56, 1996.

Menabde, M. and Sivapalan, M.: Linking space-time variability of runoff and rainfall fields: a dynamic approach, Adv. Water Resour., 24, 1001-1014, 2001.

Milly, P. and Eagleson, P.: Effect of Storm Scale on Surface Runoff Volume, Water Resour. Res., 24, 620-624, 1987.

Palecki, M. A., Angel, J. R., and Hollinger, S. E.: Storm Precipitation in the United States, Part I: Meteorological characteristics, J. Appl. Meteorol., 44, 933-946, 2005.

Reggiani, P. R. and Rientjes, T. H. M.: Flux parameterization in the Representative Elementary Watershed (REW) approach: application to a natural basin, Water Resour. Res., 41(4), W04013, doi:10.1029/2004WR003693, 2005.

Reggiani, P. and Rientjes, T. H. M.: Closing horizontal groundwater fluxes with pipe network analysis: an application of the REW approach to an aquifer, Environ. Modell. Softw., 25, 1702-1712, doi:10.1016/j.envsoft.2010.04.019, 2010.

Renard, K. G. and Freimund, J. R.: Using monthly precipitation data to estimate the R factor in the revised USLE, J. Hydrol., 157, 287-306, 1994.

Tsubo, M., Walker, S., and Hensley, M.: Quantifying risk for water harvesting under semi-arid conditions, Part I. Rainfall intensity generation, Agr. Water Manage., 76, 77-93, 2005.

Van Dijk, A. I. J. M., Bruijnzeel, L. A., and Rosewell, C. J.: Rainfall intensity-kinetic energy relationships: a critical literature appraisal, J. Hydrol., 261, 1-23, 2002.

Van Dijk, A. I. J. M., Meesters, A. G. C. A., Schellekens, J., and Bruijnzeel, L. A.: A two-parameter exponential rainfall depthintensity distribution applied to runoff and erosion modeling, J. Hydrol., 300, 155-171, 2005. 
Woolhiser, D. A. and Osborn, H. B.: A stochastic model of dimensionless thunderstorm rainfall, Water Resour. Res., 21, 511-522, 1985.

Zeng, N., Shuttleworth, J. W., and Gash, J. H. C.: Influence of temporal variability of rainfall on interception loss, Part I. Point analysis, J. Hydrol., 228, 228-241, 2000.
Zhang, G. P., Fenicia, F., Rientjes, T. H. M., Reggiani, P., and Savenije, H. H. G.: Modeling runoff generation in the Geer river basin with improved model parameterization to the REW approach. Phys. Chem. Earth, 30(4-5), 285-296, 2005. 